Revista Tecné, Episteme y Didaxis: TED. Año 2014, Número Extraordinario. ISSN Impreso: 0121-3814, ISSN web: 2323-0126

Memorias, Sexto Congreso Internacional sobre Formación de Profesores de Ciencias. 08 al 10 de octubre de 2014, Bogotá

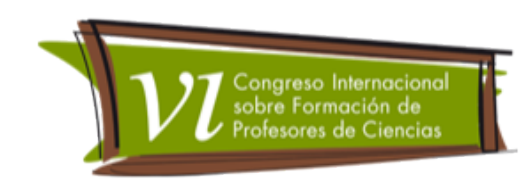

\title{
La legalización de la droga en Colombia. Controversia socio científica en el marco de formación de docentes en ejercicio
}

Rodríguez H. Blanca' , Martínez P. Leonardo F².

Categoría 2. Trabajo de investigación

\section{Resumen}

Se presentan algunos resultados de un estudio exploratorio sobre la formación de Pequeños grupos de Investigación (PGI) de docentes en ejercicio en el marco del proyecto internacional colombo-Brasilero de formación de docentes en la interacción universidad escuela. Este PGI está formado por 13 docentes de diferentes áreas, la orientadora y coordinadora de la institución, quienes atienden población de jóvenes y adultos en un horario nocturno en un colegio distrital de Bogotá. La CSC que se aborda debido a las cualidades de la población en estudio es "La legalización de la droga en Colombia: un mal menor para contrarrestar uno mayor".

\section{Palabras clave}

Relaciones CTSA, legalización de la droga, formación de docentes, formación ciudadana.

\section{Introducción}

En el marco del proyecto Colombo - Brasilero de formación de docentes uno de los referentes es el enfoque Ciencia Tecnología Sociedad y Ambiente (CTSA) que constituye la base para el desarrollo de investigaciones innovadoras a la luz de los objetivos de la educación científica y tecnológica, las políticas educativas, el diseño de currículos alternativos que promuevan el pensamiento crítico de docentes y estudiantes (Martínez y Parga, 2013).

Los avances científicos y tecnológicos al impactar y generar cambios sociales en forma acelerada invita a la escuela a recuperar su papel dinamizador, capaz de responder a los desafíos de este nuevo siglo, de tal manera que promueva y genere la reflexión

\footnotetext{
${ }^{1}$ Docente catedrática de Química, Universidad Pedagógica Nacional, Bogotá - Colombia. Estudiante de doctorado interinstitucional en educación. blanquita31@gmail.com Grupo Alternaciencias.

2 Profesor Departamento de Química, Universidad Pedagógica Nacional, Bogotá- Colombia. Doctor en Educación para ciencia. Grupo Alternaciencias. lemartinez@pedagogica.edu.co
} 
Revista Tecné, Episteme y Didaxis: TED. Año 2014, Número Extraordinario. ISSN Impreso: 0121-3814, ISSN web: 2323-0126

Memorias, Sexto Congreso Internacional sobre Formación de Profesores de Ciencias. 08 al 10 de octubre de 2014, Bogotá

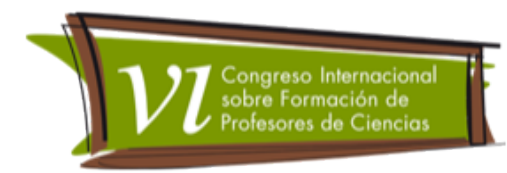

sobre el uso inteligente de los avances científicos y tecnológicos. De esta manera, la universidad ofrece a la escuela herramientas que le permitan al docente incluir en las clases de ciencias situaciones controvertidas como son las cuestiones sociocientíficas (CSC), que le permitan analizar desde una perspectiva argumentativa la forma como el hombre a través de las herramientas tecnológicas han modificado el ambiente.

En este contexto el presente trabajo constituye una investigación en desarrollo y tiene como objetivo analizar el desarrollo de un PGI de profesores interesados en abordar la CSC sobre legalización de la droga en Colombia.

Como fundamento del trabajo se considera que la sociedad está inmersa en un profundo proceso de transformación, caracterizado por el consumismo extremo, la falta de valores de nuestros mandatarios, las continuas luchas políticas por el poder y la falta de ciudadanía que no se ha podido consolidar a través de la escuela. Una de las características de la sociedad es el nivel de formación de sus ciudadanos y de su capacidad de innovación, emprendimiento y participación en las decisiones que los afecten, bien sean de naturaleza local, regional, nacional o global, lo que hace necesario que los docentes como profesionales actualicen constantemente sus conocimientos, sus competencias y aprendizajes que le permiten desempeñarse asertivamente (Marcelo, 2007).

Imbernon (2012) comenta que la formación de docentes ha estado centrada en la investigación sobre el profesorado y otra centrada en el profesorado, la primera ha proporcionado estudios sobre modelos de formación, fracaso escolar, principios educativos, aspectos de desprofesionalización, profesor novel, profesor experto, aplicación del conocimiento didáctico del contenido, etc., y la segunda ha desarrollado nuevos procesos de prácticas educativas, formativas, de elaboración de proyectos, materiales y de reflexión sobre la propia práctica al desempeñarse como profesor investigador inmerso en un proyecto de innovación dentro de la propia institución escolar donde se desempeña, la cual le permite trabajar en equipo, tomar decisiones colaborativas, desarrollar democráticamente el currículo, relacionar la teoría (investigación en la universidad) y la práctica (de aula); todo esto favorece el desarrollo personal y profesional del profesor.

La división entre la universidad y la escuela ha sido caracterizada por los trabajos de Lüdke y Cruz (citado por Batista, 2013) quienes aluden a la fragilidad de la formación de los profesores en las licenciaturas al ser poco investigativas y frágiles teóricamente, así mismo como el poco acercamiento de la universidad a la escuela al considerar la investigación como un privilegio de la universidad; según las autoras los profesores de 
Revista Tecné, Episteme y Didaxis: TED. Año 2014, Número Extraordinario. ISSN Impreso: 0121-3814, ISSN web: 2323-0126

Memorias, Sexto Congreso Internacional sobre Formación de Profesores de Ciencias. 08 al 10 de octubre de 2014, Bogotá

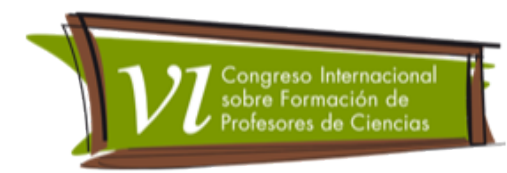

escuela están más habilitados para percibir problemas que le afligen a esos niveles de enseñanza, no son preparados en su formación universitaria para investigar y para ejercer su autonomía profesional, así las autoras sugiere realizar trabajos en conjunto, entre los profesionales de la escuela y los investigadores universitarios.

El PGI formado se analizará bajo la orientación de la teoría de Pierre Bourdieu, que muestra la lucha de los profesores de la institución por la autonomía de este espacio social de formación docente, que desea abordar un tema específico que no solo se aborda como tema de lucha diario, sino que se vive, constituyéndose en el escenario propio de la formación de ciudadanía donde el consumo, venta y comercialización de sustancias psicoactivas es desmedido.

A la luz de la teoría de Bourdieu, se estructura el campo escolar, entendido como un espacio social de luchas, regido por leyes y propiedades específicas que tiene la institución acorde a las funciones propias de toda escuela, donde los docentes desean tener y acumular propiedades distintivas respetando las leyes de este espacio, pero generando conocimiento acorde a las necesidades de la misma, esperando ser reconocidos al crear y recrear nuevas prácticas pedagógicas que le permitan enseñar y aprender de sí mismos, consolidando de esta manera, un instrumento de reflexión y orientación para enfrentar la realidad escolar, inmersa en presiones internas e inferencias externas ilegitimas, donde el habitus del maestro sea el de investigador.

Peter cohen (citado por Muñoz, 2012), autor de Drugs as social construct, considera que las razones científicas del porqué las personas consumen drogas ilícitas fue determinado por un grupo de médicos del siglo XIX que catalogaron algunas drogas como ilícitas de uso no médico, dando paso a que el consumidor moderno no puede hacer uso libre de determinadas sustancias y que por tanto se vean obligados a consultar primero a un "corredor de la droga" que produce a su vez un monopolio casi total de estas.

\section{Metodología}

El presente estudio exploratorio sobre la formación de Pequeños grupos de Investigación (PGI) de docentes en ejercicio se realiza a través de una metodología microetnográfica (etnografía de la comunicación), es una investigación cualitativa interpretativa, que describe y analiza el cambio discursivo que se genera al asumir CSC y trabajar en equipo interdisciplinar de docentes. Se están adelantando registros fotográficos, entrevistas, diarios de campo, grabaciones de los encuentros y participaciones de los representantes de la universidad con los docentes del PGI. 
Revista Tecné, Episteme y Didaxis: TED. Año 2014, Número Extraordinario. ISSN Impreso: 0121-3814, ISSN web: 2323-0126

Memorias, Sexto Congreso Internacional sobre Formación de Profesores de Ciencias. 08 al 10 de octubre de 2014, Bogotá

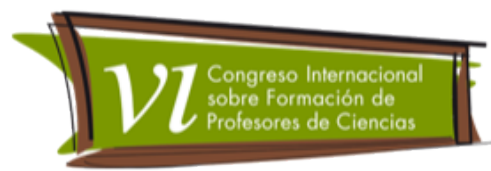

Este proyecto se desarrolla en un colegio público del sur de la Ciudad de Bogotá, el Cedid Guillermo Cano Isaza en la jornada nocturna, el cual atiende jóvenes y adultos de estrato socio económico bajo (cero a dos) caracterizados por la pobreza, el desplazamiento, la falta de oportunidades, la familia disfuncional, la reinserción de grupos al margen de la ley y especialmente por el consumo de sustancias psicoactivas, este último como característica predominante que hace que se consolide como un sub-campo del campo educativo, ya que se generan organizaciones internas que luchan por el poder y el control del microtráfico, haciendo que la academia pase a un segundo plano en los intereses de los estudiantes, lo que exige del profesor un liderazgo que permita fortalecer el papel de la escuela como formadora de ciudadanía y se reivindique el maestro como tejedor de sociedad e investigador de su propio espacio de trabajo.

Al utilizar a Bourdieu como herramienta de análisis de la realidad de la formación de docentes, y como forma de comprender la lucha por el monopolio de las drogas, suministra al PGI herramientas para analizar la CSC a la luz de los movimientos sociales actuales, de la política pública y del establecimiento de marcos de referencia científicos, políticos, educativos y culturales que posibilitan al maestro de nuevas herramientas para tomar decisiones acordes al campo en el que se desempeña. Las actividades que se encuentran en desarrollo son:

1. Taller de sensibilización por el trabajo en equipo e interdisciplinar, así como la necesidad de elegir una CSC como eje articulador del trabajo a realizar.

2. Caracterización y discusión alrededor de experiencias docentes al abordar CSC en trabajos de investigación realizados en la universidad.

3. Realización de debates en torno a la CSC elegida e identificación por parte del investigador del tipo de discurso empleado por los docentes

4. Socialización de artículos, corto metrajes y debates públicos realizados en los medios de comunicación en torno a la CSC.

5. Realización de encuestas a estudiantes para determinar y caracterizar la población consumidora de sustancias psicoactivas

6. Diseño de una secuencia didáctica basada en la CSC que permita la formación interdisciplinar de docentes.

7. Evaluar el trabajo realizado en el PGI a través de un debate sobre la CSC, que permita al investigador analizar los argumentos generados por cada uno de los participantes, al tomar posicionamiento ante la CSC. 
Revista Tecné, Episteme y Didaxis: TED. Año 2014, Número Extraordinario. ISSN Impreso: 0121-3814, ISSN web: 2323-0126

Memorias, Sexto Congreso Internacional sobre Formación de Profesores de Ciencias. 08 al 10 de octubre de 2014, Bogotá

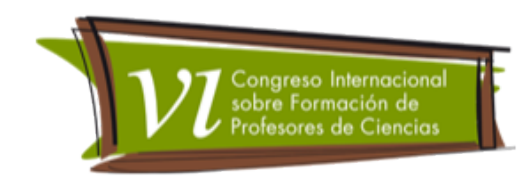

\section{Algunos Resultados}

1. Consolidación del PGI, concientización de la importancia de trabajar en equipo y determinación de la CSC a trabajar acorde a las características de la población nocturna.

2. Realización de un primer debate, cuyo objetivo era conocer la posición de cada uno de los docentes en cuanto a la consideración de la legalización de la droga en Colombia, donde se devela la presencia de argumentos superficiales basados en el sentido común, lo que manejan los medios de comunicación y sus propias ideologías. Al realizar lecturas de noticias sobre la temática en cuestión, se socializan los artículos y se empieza a generar cambios de posicionamiento respecto a la cuestión controvertida, así como la necesidad de informarse o tener referentes académicos sobre la temática.

\section{Conclusiones}

El PGI está formado por 13 docentes de diferentes áreas del conocimiento, la orientadora y coordinadora que actúa como docente de la institución y como representante de la universidad.

Al asumir CSC los docentes desarrollan habilidades al tomar decisiones, al argumentar y cuestionar la información que viene de los medios de comunicación, de las situaciones que vive o afronta la sociedad en la que vive, promoviendo así el desarrollo del pensamiento crítico que está relacionado con "la capacidad de desarrollar una opinión independiente, adquiriendo la facultad de reflexionar sobre la sociedad y participar en ella"(Jiménez-Aleixandre citado por González, 2012.)

\section{Referencias bibliográficas}

Batista S. J, Pinto, W. P y Cattani, D.G. (2013). Um estudo exploratório internacional sobre o distanciamento entre a escola e a universidade no ensino de ciências. Investigações em Ensino de Ciências, 18(2), p. 365-383.

González R, H. (2012). Controversias sociocientíficas para fomentar el pensamiento crítico en docentes. Actas III Jornadas de Enseñanza e Investigación Educativa en el campo de las Ciencias Exactas y Naturales. Facultad de Humanidades y Ciencias de la Educación. Universidad Nacional de La Plata. La Plata, 26, 27 y 28 Septiembre $2012 \quad-\quad$ ISSN $22508473 \quad$ Sitio web: http://jornadasceyn.fahce.unlp.edu.ar/actas/Gonzalez\%20Rojas.pdf/view 
Revista Tecné, Episteme y Didaxis: TED. Año 2014, Número Extraordinario. ISSN Impreso: 0121-3814, ISSN web: 2323-0126

Memorias, Sexto Congreso Internacional sobre Formación de Profesores de Ciencias. 08 al 10 de octubre de 2014, Bogotá

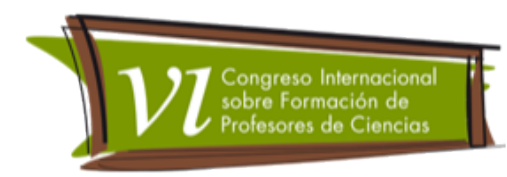

Imbernón Muñoz, F. (2012). La investigación sobre y con el profesorado. La repercusión en la formación del profesorado, ¿̇cómo se investiga? Revista Electrónica de Investigación Educativa, 14(2), 1-9. Consultado en http://redie.vabc.mx/voll 4no2/contenido-imbernon2012.html

Marcelo, C. La formación docente en la sociedad del conocimiento y la información: avances y temas pendientes. olhar de professor, ponta grossa, 10(1): 63-90, 2007. disponível em http://www.vepg.br/olhardeprofessor.

Martinez, L. y Parga, D. (2013). La emergencia de las Cuestiones sociocientíficas en el enfoque CTSA. Revista Góndola. 8(1), p 23- 35.

Muñoz R, M. (2012). Contra el determinismo farmacológico: sociología de las drogas y reflexividad. Sociedad Hoy 23. p. 21-31.

Solbes, M. y Torres, N. (2013). ¿ ¿Cuáles son las concepciones de los docentes de ciencias en formación y en ejercicio sobre el pensamiento crítico? Tecné, Episteme y Didaxis 33. p. 61-85. 